This item was submitted to Loughborough's Research Repository by the author.

Items in Figshare are protected by copyright, with all rights reserved, unless otherwise indicated.

\title{
Taught not caught: exploring male adolescent experiences of explicitly transferring life skills from the sports hall into the classroom
}

PLEASE CITE THE PUBLISHED VERSION

https://doi.org/10.1080/2159676X.2018.1519717

\section{PUBLISHER}

(C) Taylor \& Francis

\section{VERSION}

AM (Accepted Manuscript)

\section{PUBLISHER STATEMENT}

This is an Accepted Manuscript of an article published by Taylor \& Francis in Qualitative Research in Sport, Exercise and Health on 19 September 2018, available online: http://www.tandfonline.com/10.1080/2159676X.2018.1519717.

\section{LICENCE}

CC BY-NC-ND 4.0

\section{REPOSITORY RECORD}

Allen, Georgia, and Daniel Rhind. 2018. "Taught Not Caught: Exploring Male Adolescent Experiences of Explicitly Transferring Life Skills from the Sports Hall into the Classroom”. figshare. https://hdl.handle.net/2134/38049. 
Taught Not Caught: Exploring Male Adolescent Experiences of Explicitly

Transferring Life Skills from the Sports Hall into the Classroom

Georgia Allen ${ }^{1}$ and Daniel Rhind ${ }^{2}$

${ }^{1}$ Faculty of Health and Life Sciences, Northumbria University

Newcastle upon Tyne, UK

${ }^{2}$ Department of Life Sciences, Brunel University London

Uxbridge, London, UK

Corresponding author: Georgia Allen

Email: georgia.allen-baker@northumbria.ac.uk

Phone: (0191) 2273032 


\title{
Taught Not Caught: Exploring Male Adolescent Experiences of Explicitly \\ Transferring Life Skills from the Sports Hall into the Classroom
}

\begin{abstract}
Using sport domains to teach young people a wide range of life skills is not new, however there has been a recent emergence of research on life skills transfer, particularly from a sport environment into other life domains (e.g., school or work). As research in this field is still in its infancy, how younger adolescents effectively learn life skills or transfer skills into other life domains is still not fully understood. Therefore, the purpose of this study was to examine the life skill learning and transfer experiences of 20 male participants (12-13 years of age) in a school context. The TransferAbility Programme (TAP) was delivered in a state funded secondary school in London, UK, where the participants attended the programme directly after teaching hours, once weekly, for one academic year. The programme was a multi-faceted intervention, which sought to explicitly teach male participants life skills through sporting activities and facilitate transfer opportunities. Semi-structured interviews were conducted with 18 participants, one parent and one teacher at the end of programme and analysed using a thematic approach. Findings suggest that the use of explicit strategies and group discussions aid the learning and transfer of life skills. However, school-based, life skills programmes of a similar nature should consider increasing participant autonomy during the programme development stage in order to maximise the personal value and relevance placed on the life skills. Partnerships across the whole school environment also need to be evident in order to provide frequent opportunities for skill transfer.
\end{abstract}

Keywords: life skills, transfer, after-school programme, sports hall, classroom

\section{Introduction}

Sport is a popular vehicle in which to promote positive youth development (PYD) (Danish 2002; Hellison 2003; Lerner et al., 2005), as it has far reaching appeal, with 
millions of young people engaging in sporting activities on a regular basis. A recent surge in teaching young people a plethora of life skills through sport participation has increased the demand for sports based, positive youth development programmes. Programmes such as Sports United to Promote Education and Recreation (SUPER: Danish, 2002), Teaching Personal and Social Responsibility (Hellison, 2003) and The First Tee (Weiss, 2006) have paved the way for smaller and more localised programmes to be delivered in schools and across local communities.

The notion that sport can provide young people with the skills (e.g., enhanced academic achievement, improved communication and enhanced self-confidence) needed to prepare them for their life ahead has become a widespread belief (FraserThomas, Côté and Deakin, 2005). Sport literature commonly defines life skills as 'those skills that enable individuals to succeed in the different environments in which they live, such as school, home and in their neighbourhoods' (Danish, Forneris, Hodge and Heke, 2004: 40), with life skills being physical, behavioural, or cognitive in nature (Papacharisis, Goudas, Danish and Theodorakis, 2005).

However, for sport to be beneficial to the millions of young people that regularly participate, the life skills that are developed must be transferred beyond sporting domains (Gould and Carson, 2008; Kendellen and Camiré, 2017). In the absence of a universal definition, Pierce, Gould and Camiré (2017: 11) operationalised life skills development as:

The ongoing process by which an individual further develops or learns and internalizes a personal asset (i.e., psychosocial skill, knowledge, disposition, identity construction, or transformation) in sport and then experiences personal change through the application of the asset in one or more life domains beyond the context where it was originally learned. 
Sporting environments can provide young people with challenges not evident in other contexts such as the classroom (Turnnidge, Côté and Hancock, 2014), allowing young people the opportunity to acquire skills that can be utilised in non-sport domains (Weiss, Stuntz, Bhalla, Bolter, and Price 2013). However, participation alone may not be sufficient to promote positive development (Hodge, Danish, Forneris and Miles 2016; Holt, Tink, Mandigo and Fox, 2008). For sport to have any impact on youth development, a complex interaction of contextual and social factors is required (Turnnidge et al., 2014). With this in mind, the way in which life skills programmes are designed is fundamental to how young people acquire life skills in sporting environments and how skills are transferred into other contexts. Yet, sport programmes or interventions are often badly structured and/or implemented and therefore the full learning potential of life skills may be undermined (Danish et al., 2004). Furthermore, how programmes should be designed and structured continues to be an ongoing discussion (Hodge, Danish and Martin, 2013; Turnnidge et al, 2014). Although factors such as programme structure, positive climate, discussing life skills and transfer as well as practice and transfer opportunities (Author et al., 2015; Bean et al., 2018; Holt et al., 2017) have been identified as elements that are conducive to life skill development.

Previously, programmes often adopted an implicit or explicit approach to teach life skills (also known as caught or taught) with arguments often made for one method at the exclusion of the other. Some researchers maintain that participation in physical activity or sport can be conducive to youth-driven learning (Camiré, Trudel and Forneris, 2009; Holt et al., 2008; Lerner et al., 2005; Weiss et al., 2013), independent from deliberate, adult-led, life skills teaching. Implicit programmes often focus on sport-specific, technique-based skills without placing any conscious effort on the acquisition or transition of life skills (Bean, Kramers, Forneris and Camiré, 2018; 
Turnnidge et al., 2014). As a result, programmes adopting an implicit approach believe young people can be deliberate producers of their own learning and development and therefore, do not need to rely on adults (Jones and Lavallee, 2009; Lerner et al., 2005). Opportunities to learn life skills can occur in sporting contexts, nevertheless, it has been argued that the automatic learning of life skills should not be assumed (Bean and Forneris, 2016; Camiré et al., 2012) particularly in young children. Fundamental to the explicit approach is the concept that young people may require guidance, to be taught what life skills are and how to use them in different life domains. Thus, it is possible that young people implicitly learn life skills, if a suitable and conducive learning climate is in place (Holt et al., 2017). Whilst Bean and colleagues (2018) view opposing approaches (i.e., implicit vs explicit) as an artificial dichotomy, it would appear that life skill learning is more probable when programme leaders adopt an explicit approach to teaching (Bean et al., 2018; Holt et al., 2017). Hence, the teacher/coach needs to utilise intentional teaching scenarios and provide deliberate opportunities for life skill learning (Bean, Kendellen and Forneris, 2015; Gould and Carson, 2008; Trottier and Robitaille, 2014).

Moving away from the implicit versus explicit debate, an integrated approach to life skill learning has been advocated more recently (Holt et al., 2017; Pierce, Gould and Camiré, 2017; Turnnidge et al, 2014), whereby researchers and coaches adopt a continuum of implicitness/explicitness to facilitate life skill learning and transfer (Bean et al., 2018). Moreover, whilst transfer is recognised as a necessary component and an essential outcome of the life skill process, it is also imperative to acknowledge the difficulty young people experience when transferring skills. Young people often fail to recognise that life skills learned in sport programmes can be used effectively in different contexts (Author et al., 2015). In reality, life skill learning is complex, and 
transfer can prove to be problematic for many individuals, particularly as life skills do not transfer very readily, as transfer occurrence is usually reliant on the similarity of contexts (Pierce et al., 2017), which requires young people to recognise similarities.

Likewise, in order for transfer to occur opportunities that facilitate transfer need to be available. The opportunity to apply skills in various contexts is essential for life skill transfer (Camiré et al., 2012) but one that is often assumed, overlooked or simply not provided. Even in situations where opportunities are provided, research advocates that young people often require support to transfer skills (Author et al., 2015; Bean et al., 2015; Martinek and Lee, 2012). Several strategies have been previous utilised, including building collaborations between intervention deliverers and institutions to embrace skill use (Martinek and Lee, 2012) and facilitating group discussions to maximise support from peers (Author et al., 2015). For further details on the model for life skills transfer, see Pierce and colleagues (2017).

Furthermore, we argue that the age of the participants could be an important factor when adopting an implicit/explicit approach. Camiré and colleagues (2012) found that high school coaches in Canada believed that many of their athletes did not have the cognitive maturity to understand the concept of transfer and that transfer probably occurred in the later stages of life. Interestingly, this may be why youth-based literature tends to support an explicit approach (Bean and Forneris, 2016; Gould and Carson, 2008; Weiss et al., 2013). Younger adolescents also have limited domains and contexts in which to transfer life skills. For example, young people attending school have not experienced environments such as the workplace or higher education which may explain why transfer can occur more frequently in the later stages of life. Recent studies advocating the use of an implicit approach to life skill teaching (Camiré and Trudel, 2010; Chinkov and Holt, 2015; Jones and Lavallee, 2009; Jones et al., 2011) 
tend to include older adolescents, who are more likely to have access to a wider range of contexts in which to transfer life skills.

In summary, despite a recent emergence of research examining the transfer process and the development of recent frameworks, the literature is still unsure of the processes related to life skill transfer. Whilst reports on structured life skill programmes are encouraging and indeed needed, there remains a lack of research examining the ways in which young people learn and apply such skills (Hodge et al., 2016). The uncertainty surrounding skill transfer needs to be addressed to ensure future life skill interventions are well designed and effective. Therefore, the purpose of this study was to explore the learning and transfer experiences individuals in the early stages of adolescence (i.e., Year 8, 12-13 years old) encounter within an academic context.

\section{Method}

\section{Context}

The TransferAbility Programme (TAP) was a multi-faceted intervention designed to facilitate the acquisition and transfer of life skills through an after-school, sports-based programme. TAP consisted of 23 once weekly sessions, lasting 75 minutes in duration. The number of sessions was determined by the number of weeks the sports facilities were available at the school within the academic year. The programme was designed to teach the participants seven interpersonal skills they could apply in various academic domains in an attempt to reduce negative behaviour and improve engagement in the classroom. Careful consideration was given when selecting the life skills as there were a vast number of skills that could have been included in the programme. The rationale for selecting the seven skills was largely based on a review of school engagement and the sport-related life skills literature. The school also identified a set of skills based on 
a needs analysis and the importance placed on particular skills. After a meeting with the school, whereby a workable timetable for the programme was confirmed, the final seven life skills were agreed.

Each life skill was then taught through participating in an appropriate sport (Table 1) by an experienced sport coach (six coaches in total delivered on the programme), who had a minimum of five years coaching experience in that particular sport and were familiar with using an explicit approach of teaching life skills. The six coaches had previously attended life skills training through their coaching qualifications or professional development. All the coaches attended a training morning/briefing before the programme started to ensure they were acquainted with the school and understood the nature of the programme.

Each life skill was taught over a three-week period so the participants had time to dedicate to learning the life skill. The initial session introduced the life skill to the group. The participants discussed their current knowledge of the skill with the lead author in a classroom-based setting which lasted approximately 30 minutes. The participants spent the remainder of the session actively participating in various physical tasks, drills and games designed to maximise the opportunities to use the life skill. For example, in goalball, the participants were blindfolded for all or parts of each task/drill which compelled them to concentrate on their verbal communication. At the end of the session, the participants were encouraged to think about transferring the skill into the classroom and utilise opportunities to use the skill outside the sports hall.

The second session would consist of 75 minutes spent in the sports hall, actively engaging in games and drills (e.g., such as engaging in a repetitive throwing task in Frisbee which required the participants to solely focus on the task when learning about persistence), that allowed the students to practice the life skill. Opportunities to tell the 
group about any transfer experiences and ask the lead author questions relating to life skill use were provided throughout. Finally, the third session included 45 minutes of adapted game play that encouraged life skill application (e.g., including rules that required the participants to use communication more effectively). The participants then participated in a focus group for the remainder of the session, allowing them to discuss individual learning and transfer experiences across academic settings. Whilst the focus groups offered insightful information around the students' ability to transfer the specific skill during the three-week period, they were primarily used to facilitate life skill transfer through peer communication and became a fundamental part of the programme. The focus groups were not designed to be used as a data set.

\section{Theoretical Frameworks}

Gould and Carson's (2008) model was used to guide the development and design of the programme, particularly the information on internal and external assets, developing a sport participation experience, positive and negative outcomes, and transferability of life skills. Petitpas and colleagues (2005) argue youths are more likely to experience positive development in the presence of (1) an appropriate environment (context), (2) caring adults (external assets), and (3) they are provided opportunities to learn life skills (internal assets). The framework was used throughout the implementation of the programme and all three elements were embraced. It was important that the participants could spend time with caring adults (e.g., the researcher, coaches and teachers) throughout the programme.

The lead author developed a positive relationship with the participants throughout the programme but was only at the school one afternoon per week. During the rest of the school week, the participants were encouraged to see the female teacher 
responsible for their pastoral care (in this instance it was the Head of Year 8). This senior teacher was present during the after-school sessions to oversee the programme from an administrative perspective and provide a school contact (i.e., a caring adult) the participants could seek advice and support from on a daily basis if needed. It is worth nothing that this teacher did not teach the participants in any capacity.

\section{Philosophical Assumptions}

This study adopted an interpretivist approach in order to gain a deeper understanding of the transfer process that the participants experienced (Smith and Sparkes, 2014). Stemming from a relativist ontological position and informed by subjectivist epistemology, our position that reality is subjective and therefore, each individual, experiences a different reality even when the circumstances or environment are the same. Understanding life skill transfer was essential to understand the individual experience of transfer but also to gain insight into the social and cultural environment of life skill transfer in the school setting.

\section{Participants}

Twenty eligible participants engaged in the programme, although one participant withdrew after 6 weeks as he was excluded from the school. Purposive sampling ensured all the students were male and in the second year of secondary education in the UK ( 12-13 years old) as it was judged timely to make an impact on their attitudes to school at this age. The programme only targeted male students for several reasons but mainly due to the longstanding political focus on male attainment and engagement, both at the school and on a national level (Smith, 2003). Although this paper is not focused 
on the academic attainment results, all participants were also identified by the school as underachieving in at least once core subject (English, Maths and/or Science).

\section{Data Collection}

After receiving ethical approval from the University Research Ethics Committee, information sheets were provided to the school, parents and participants. The school's senior management team provided approval and parental/guardian consent and participant assent were also obtained. The participants were informed of the right to withdraw at any time without consequence and confidentiality and anonymity were assured in line with child protection guidelines.

A semi-structured interview schedule was developed based on previous life skill research (e.g. Camiré and Trudel, 2010; Camiré et al., 2009; Holt et al., 2009; Gould and Carson 2008) and qualitative research methodology (e.g. Sparkes and Smith 2014) to ensure key topics were covered. The interview guide explored the participants' experiences during the programme and the perceived nature of learning and transfer of the seven life skills. Each participant confirmed their assent at the start of the interview and introductory questions sought to reassure the participants. Questions then addressed the nature, perceptions and personal experiences related to the programme and the life skills (i.e. the perceived learning of each life skill, examples of transfer and their experiences of each skill transference). The interview guide was initially piloted with a 12-year-old male student who was not involved in the programme. The pilot interview was not included in the final sample but did allow for minor changes to be made to the interview guide.

Eighteen individual semi-structured interviews were conducted with the participants at the end of the school year as one participant was ill during the interview 
phase and therefore not available for interview. Interviews lasted on average 38 minutes. The school teacher (Head of Year 8), who was mentioned above and oversaw the programme each week, and one parent were also interviewed to provide an insight on the programme and the participants' ability to transfer of skills from an adult's perspective. All parents were invited to participate in an interview via a letter sent out by the school, however only one parent accepted the invite and attended the interview. These interviews lasted 61 and 43 minutes respectively. All interviews were conducted in a private meeting room on the school premises and voice recorded. Whilst this provided a familiar, convenient and safe environment, some participants were initially concerned that their teachers may be given information arising from the interviews. Any concerns the participants had were mitigated by the first author who emphasised confidentiality and anonymity (in line with child protection guidelines).

\section{Interview analysis}

All interviews were conducted within one week, were transcribed within three weeks of them taking place and pseudonyms were used to ensure anonymity. Clarke and Braun's (2014) recursive six-phase process was adopted. Initially, this involved immersion in the data by reading each transcript several times (phase 1). During this phase, an overall impression of the data were formed and notes were made to support this process. Areas of particular interest were identified through the adoption of a simple colour coding system (i.e., hard copy/pen and paper format) (phase 2) and a mix of semantic and latent codes were produced (phase 3 ). Codes were regularly modified and developed as a better understanding of the data was formed. This back and forth process occurred several times. Once the first author was satisfied the codes represented the data, they were combined together to form themes. The actively sought themes were 
then reviewed by the research team to ensure coherency (phase 4), appropriately defined and named accordingly (phase 5). Again, this phase was time consuming and involved renaming the themes several times. Conscious of having developed the programme, the first author reflected regularly on any personal bias and discussed any concerns with the second author, who formed the role of a critical friend, and challenged any bias throughout the analysis process. Finally, phase 6 involved presenting the results for publication.

\section{Methodological rigour}

The authors are aware of the debate surrounding inter-rater reliability and its effectiveness in determining rigour (Smith and McGanonon, 2017), however the researchers did met regularly throughout the analysis phase, not necessarily to ascertain rigour but rather to ensure data processes were followed, to discuss the findings and reduce any personal bias during the coding phase.

The lead author was present in the school one afternoon every week, for one full academic year ensuring prolonged engagement and persistent observations. The second author acted as a 'critical friend' (Sparkes and Smith, 2014), whereby the researcher had no contact with the participants or the school so could help guard against researcher bias, therefore, fulfilling the role of a theoretical sounding board as highlighted by Sparkes and Smith (2014). The critical friend ensured the lead author was aware of relationships with the participants, prevented any potential over-rapport and enhanced reflexive self-awareness processes.

\section{Findings}

\section{Taught not caught}


TAP adopted an explicit approach when teaching the seven life skills, mainly due to the nature and school setting of the programme. During the interviews, many of the participants highlighted the importance of using an explicit approach in order to recognise the skills included in the programme (e.g., teamwork and communication). David explained how the explicit programme structure raised awareness of the skills:

There weren't any sessions where you didn't learn something, like in every session you learned stuff because the coaches would tell us about the skills and then get us to do things where you would practice the skill whilst doing sport and it has helped in some way or another. Like, I already knew that you used teamwork in PE, but I learned new stuff about teamwork, so I can now use it in class. I didn't know that you could learn about persistence and discipline when playing sports.

When probed further, David highlighted the importance of using the explicit approach: 'I just didn't know, like PE is about sports and being active. I didn't know that sport sessions could help you in lessons like maths and science until the coaches told us'.

Throughout his interview, Mohammed also spoke positively about the programme. As a carer for his mother, Mohammed missed school on a regular basis but consistently attended school on the day the programme was delivered. When asked what he thought of TAP, Mohammed said:

I felt privileged to be part of the group because um, some people like don't do this kind of stuff. I felt relived because without this, I wouldn't be focusing as much as I do in lessons now. I learned to enjoy myself and be part of the class more. I learned stuff that I didn't know about, like persistence, like the idea of keep going helped me the most. TAP helped me at school, because um, now I've got different routines and I know a lot of stuff about team work, discipline and other things that I can use when I need them. 
When asked 'how do you know about these skills now?' Mohammed acknowledged the importance of deliberate teaching strategies and peer support for life skill transference:

The coaches told us about the skills and how to use them when we were playing the sports and stuff and then we would talk about the skills as a big group and we would talk about how we would use the skills in the classroom and then we talk the next time about if we had used the skills during the week. That really helped but it was the coaches that helped the most.

The explicit approach appeared to be beneficial to the participants when learning the life skills, but life skills must also be transferred into other domains (Gould and Carson, 2008; Papacharisis et al., 2005). The programme focused on transfer within the school environment with the participants regularly discussing how and when to transfer the life skills in to the classroom. The participants discussed how the focus groups played a role in the explicit learning and transfer of the life skill. The participants all recognised the importance of the focus groups in the end of programme interviews as Jacob highlights:

I liked the group talks because the feedback, it showed like if you'd learned in the lesson like if you knew what you were doing in the sessions to succeed, if you didn't really understand goal setting you could in the focus groups say I didn't really understand this and then you could understand better afterwards because, like, the other boys would explain it in a way I could understand better.

Similarly, Kaseem states:

You got to empathise with people, see things from different perspectives and see how other people use the skills and it affected how you use it, you could use it like, the communication, incorrectly and someone else says they use it this way, it helped you to use it in the right way. 
Mahmud also recognised the importance of peer support during the focus groups:

Hearing other people's ideas made you think about the skills more. When we talked about the skills, erm just us, it helped because it was something my friends were using, and they helped me to know how to use it.

It appears the interaction and sharing of ideas amongst peers was an effective way of supporting the explicit method adopted during the programme.

Although all the participants were able to identify examples of transference, a number of participants recognised that the transfer process was a conscious one as Firaz explained:

I did have to think about it quite a lot when using persistence and discipline but mostly persistence. Because of TAP it was in my head more to actually work hard and use the skills. It took time for me to progress and I had to think about how I should use them [the life skills] but by taking the key parts of TAP and using it in lesson time, I have done better this year.

Likewise, Ezra said:

After a TAP session I would go to lesson and start off being silly then I would think back and remember to concentrate. I would think about a lesson in class as one of the sport sessions we did and try to use the skills in a similar way. It took a long time before I could do and sometimes I still find it too hard. Sometimes I still try to be the class clown, but I definitely do it a lot less. My friends didn't find me as funny anymore but I'm glad I have changed my attitude in class because I like getting more merits and less detentions.

\section{The ability to transfer skills}


The participants were able to confidently discuss positive transfer experiences, supporting the notion that life skill learning had occurred but during the interviews it became apparent that the majority of the participants found some skills easier to use in the classroom than others. Many of the participants could identify one skill they found easier to transfer as Michael described:

Before TAP I was not concentrating well in lessons I was not achieving well in my lessons. When we did all the sessions I became more confident in concentrating on the tasks we did because I could use the techniques I learned in all my lesson. I stopped getting distracted by my friends when they were being silly or talking to me, so I took what I learned in TAP into my lessons.

\section{And Callum said:}

I learned to talk properly to people and not shout, to let other people speak. I first used it in maths, when we did group work and then in all my lessons when we did group work. I also use it when talking to my teachers. The sessions helped me to understand that shouting in the classroom doesn't help people hear what I have to say and just talking properly is better. I had to think about using it [communication skills] and sometimes it was really hard to use it but it became easier to use after a while'.

During the interviews, Ezra was the only participant who was able to recognise that he had transferred some skills, into a domain outside of school he said:

Before TAP I would go to lessons and not concentrate and try and be the class clown and make people laugh but like I think back to the session we had and some of the stuff we did, and I would remember what the coaches told us. I get a lot less detentions now. I communicate more, like I don't usually talk a lot at home I just go on the laptop like so like I probably only talk to my brother but now I have more confidence speaking and communicating with teachers, my Mum and Dad and people I don't know very well. 
It is possible that other participants did transfer the life skills outside of a school environment but given the nature of the programme thought they did not need to discuss these transfer experiences. It is also possible that due to the focus on applying these skills in the classroom setting that the participants were not aware or did not make the connection to transfer the skills into other life domains.

The participants also highlighted challenging experiences when using the life skills in the classroom. Typically one or two skills were identified as difficult to utilise, as Michael explained: 'some skills can be easy and some can be difficult to use depending on what you are best at and what you can use in the classroom.'

Idris was in agreement with Michael as he elucidated:

Some people will get the skills straight away, some people won't, like they might need more help. The goalsetting I got, the discipline I got and communication I got, I use them two the most but the self-talk and confidence stuff, no, I didn't get that at all even though we talked about it loads.

Despite all the participants perceiving an improvement in their ability to set goals at the end of the programme, many participants believed that school did not provide them with sufficient opportunities to set goals. Kaseem recognised the importance of goal setting but discussed the challenges of using it on a regular basis:

I don't think I use it that much in lessons because it depends on the topic you do. I did dreams and aspirations last year and that included goal setting but in other lessons I don't think I really need to goal set but I think I should because goal setting and persistence they go together, if I set my goal I would be more persistent to reach that goal but teachers don't really give you the time or the chances to do that. 
David recognised an improvement in his ability to use teamwork in PE but highlighted a lack of opportunities in the classroom proved problematic in the transferring of the skill:

If you were using it in sports it's the best thing ever but if you try use team work in the classroom you only ever have a couple of chances to like work in teams and it's just the same as in PE. I'm using better now in PE but not in lessons.

This suggests that transfer of skills is not only linked to the modelling and practice of life skills but is also dependent on schools providing opportunities for students to use the skills in other academic situations (see Author, (date) for more information on the enablers and barriers of transfer in school).

\section{Importance of relevance and personal value}

During the interviews, it was apparent that the participants found some skills harder to transfer than others, however, some participants simply did not try to transfer some of the skills. Adam suggests that in order for transfer to occur the participants have to place a level of personal value on the life skill and see the relevance of using the skill when he explained: 'I just don't see the point in setting myself goals, I just do things anyway, so there's no point'.

Rashad was also a participant who particularly struggled to transfer the discipline techniques into the classroom:

I don't have discipline in classroom because I don't have any respect for the teachers so that's my weakest thing. I don't see the point in using the discipline stuff we learned because I don't care what the teachers think of me if I'm honest. 
He acknowledged that the sport sessions related to discipline had been useful and that he had learned more about the skill during the programme but he simply chose not to apply the skill in the classroom. In support of Turnnidge and colleagues (2014), the value young people place on the non-sport environment is also important when discussing transfer. The coaches and teachers believed the classroom contexts and the seven life skills to be important and assumed such a skills would be transferred. Rashad did not value the classroom environment or respect his teachers, and as a result, his behaviour continued to be problematic in a classroom context.

\section{Establishing connections}

During the interview with Jacob's mother, it was clear she thought her son had engaged with the programme and, as a result, his attitude towards school had improved. When asked what she thought of TAP she replied: 'It was amazing; it helped him so much'. When ask to elaborate on how TAP had helped her son she said:

I asked him when he came home "what have you done today" and he would say boxing or some other sport that he was excited by and he would say, I learned this or I learned a new activity that we don't do in usual PE lessons. He was so excited after the sessions. Before the programme, I asked him why his grades weren't as good as they could be and he said, "Well I don't always find it interesting. I don't find the lessons interesting and I don't like the ways we are taught so I don't pay as much attention as I should." He actually said that, and it seems that through giving him a range of activities, doing different sports, talking about the new skills and learning techniques to use in the classroom and him being engaged in the programme, it has helped raise his academic grades. Because the programme taught him about important skills, he now knows how to use skills he has learned through playing sport and he uses them at home and at school. It's so obvious to me, if the programme wasn't there then maybe, maybe he would have improved this year but not as much as he has done (Jacob's Mum). 
To gain further clarification, Jacob's mum was asked why she thought TAP was different to Jacob's other sports session, for example PE and organised sports, she explained:

Jacob does a lot of sport, he really enjoys PE and he plays a lot of football, like most boys his age. I might be wrong but I think they just don't teach him skills like that, they don't tell him how sport can help him to concentrate or make him better at listening to his teachers. I haven't ever seen him do his PE lessons but I know at football it's just about being better at playing football. I think PE must be the same because he hasn't improved at school like he has this year. He hasn't used these skills at home like he is now. Like I said before he might have improved this year but the obvious difference has been this programme and how it has told him about the skills you can learn whilst being active.

The teacher responsible for the boys' pastoral care during the programme, further emphasised how she felt an explicit approach had been most appropriate for the participants:

Some of the boys are really disaffected in lessons, this is quite a challenging group of students but there is a consistent pattern with their improved behaviour during the programme, and with one student in particular the change has just been amazing in terms of when we look at him at the start of the programme and we look at him now and the conversations we are having. Don't get me wrong he is still sent out of some lessons but it's a lot less. This group of boys have seen a $44 \%$ reduction in the number of detentions this year compared to last year and he is a big part of that $44 \%$ reduction.

You must make a connection with a curriculum area and not just PE and that's the danger because they think PE is a sport and it's a practical thing that is separate from other lessons.

The teacher went on to say: 
If you are looking at impacting on something across the whole school or the wider curriculum then you need to get the students to understand and make them aware of the skills they are learning and how they can be used, the students need to be able to establish connections because they can't, they don't and they won't make connections themselves.

Both Jacob's mother and the school teacher acknowledged that the participants had not previously recognised the skills acquired through sport participation could be used in the classroom, highlighting the need for deliberate teaching strategies to be employed with younger adolescents.

\section{Conclusion and implications}

The purpose of this study was to explore the learning and transfer experiences young adolescent males encounter within an academic context. The findings of the present study are aligned with previous research supporting the explicit approach to teaching life skills (Bean and Forneris, 2016; Bean et al., 2015; Camiré et al., 2012; Theokas et al., 2008). As previously highlighted, there is nothing magical about sport but sport can be used as a vehicle to facilitate life skill learning (Danish et al., 2004; Theokas et al., 2008). Many programmes that adopt a deliberate approach often report positive findings but we argue that this is only the case as long as the programme is designed and structured to facilitate such learning (Author et al., 2015; Bean and Forneris, 2016).

The focus groups appeared to be more impactful than the lead researcher had initially realised, with the participants reporting that they had listened to their peers and respected their suggestions on transfer more than they would have done if the researcher had imparted the same information. Interestingly, the participants placed more significance on each other's experiences as they felt they could relate to each 
other. The support from peers was an instrumental in facilitating the learning and transfer for many of the participants in this study and is recognised as an important component of life skill transfer (Author et al., 2015; Pierce et al., 2017).

The interview data suggest participants had not and would not have established the links between using skills in sport and in the classroom, had they not been explicitly taught and provided with opportunities to discuss and practice life skill transfer (Pierce et al., 2017). We wholeheartedly agree with Camiré and colleagues (2012) when they say life skill learning and transfer "should not be left to chance" (p. 258) Future programmes should seek to develop and better understand the contexts in which peer learning and support are most beneficial.

The findings also suggest that the school environment, provided the participants with little opportunity to use the skills. The participants largely cited a lack of opportunities provided in the classroom setting as the main barrier for transfer. This was most apparent with goal setting despite the school highlighting goalsetting as an important skill for their students. The importance of providing opportunities for transfer to occur, especially when transfer is being encouraged in a specific environment such as at school, should not be overlooked (Author et al., 2015; Pierce et al., 2017). We recommend that future school-based programmes address this issue by forging strong programme partnerships throughout the whole school environment.

Future programmes should seek to collaborate with teachers across the school in order to facilitate a more supportive environment and to create greater connections across the curricular. A cohesive whole-school approach may help to ensure that teachers across the school are aware of programme aims, and as a result, teachers may be able to facilitate more tangible opportunities for students to practice life skill transfer within the classroom. Whilst the sports hall can provide participants with a vehicle to 
learn skills and discuss life skill transfer, it would appears younger adolescents require more explicit opportunities to practice transfer in other environments. Furthermore, this may help students construct connections for transfer across the whole school environment rather than them trying to make the transfer connections in isolation (i.e., focusing on transfer from the sports hall only).

Whilst a lack of opportunities was the most discussed barrier for not transferring the skill into the classroom, several participants also acknowledged a lack of personal value and/or relevance for not using the skill in the classroom.. This finding raises questions around adult-designed and adult-led programmes and the dilemmas this creates. The life skills included in TAP were selected by the researcher and the school, largely based on a literature review and a school-based needs analysis. It was assumed that the participants would find the life skills beneficial across the school environment. However, it appears that the participants need to place personal value on the skill and see the relevance of using the skill before they transfer the skill into a different setting. Future programmes may wish to include the participants when making choices on what skills to include. Providing participants with greater levels of autonomy over programme design may result in greater commitment to the programme, greater levels of independence and higher levels of personal value and relevance placed on the life skills.

Finally, the participants of this study acknowledged the importance of adopting an explicit approach to life skill development but the age of the participants (e.g., young adolescents), as well as the nature and setting of the programme may have had some impact on this finding. For example, the programme was conducted at the school where children are habitually taught and conditioned to learn through a variety of explicit strategies. As a result, the findings suggest that physical education contexts may be 
better suited to adopting and integrating explicit transfer strategies than sport coaching environments. In this vain, it is possible that physical educators may be missing opportunities to teach their students important life skills that could be transferred across the curricular. Further research is needed to not only understand the implicit/explicit dichotomy (Bean et al., 2015; Camiré \& Kendellen, 2016) but also consider what impact the environment may have when adopting an approach.

\section{Limitations}

TAP had several limitations that must be noted. Whilst the results of the programme are insightful, further extensive research on transfer is merited. The data collected in this study relied on the participants providing retrospective examples of life skills transfer, which may have been limiting. Despite all the participants providing examples of using the life skills in the classroom, it does not mean skill use was directly linked to TAP, and whilst the focus groups were an invaluable resource in promoting life skill transfer and provided opportunities to discuss transfer experiences, the participants may have been demonstrating understanding of life skill transfer rather than their own ability to apply the skill during the interviews.

This study adopted a fully explicit teaching approach to life skill learning and transfer. The findings indicate that this approach appeared to be effective, possibly due to the school context in which the programme took place. Yet, recent recommendations suggest using a combination of both approaches to maximise life skill learning (Bean et al., 2015; Turnnidge et al., 2014). More recently, Bean and colleagues (2017) have proposed the use of an implicit/ explicit continuum in life skill programmes. For that reason, future studies are needed to determine the optimal balance between these 
approaches (Bean et al., 2018; Bean et al., 2015; Camiré \& Kendellen 2016) with various populations in different contexts.

\section{References}

Allen, G., Rhind, D., and Koshy, V. 2015.

Bean, C.N., and T. Forneris. 2017. Is Life Skill Development a By-Product of Sport Participation? Perceptions of Youth Sport Coaches. Journal of Applied Sport Psychology 29 (2): 234-250.

Bean, C.N., and T. Forneris. 2016. Examining the importance of intentionally structuring the youth sport context to facilitate positive youth development. Journal of Applied Sport Psychology 28 (4): 410-425.

Bean, C.N., K. Kendellen, K, and T. Forneris. 2015. Moving beyond the gym: Exploring life skill transfer within a female physical activity-based life skills program. Journal of Applied Sport Psychology 28 (3): 274-290.

Bean, C.N., S. Kramers., T Forneris, and M. Camiré. 2018. The implicit/explicit continuum of life skills development and transfer. Quest, DOI: $\underline{10.1080 / 00336297.2018 .1451348}$

Braun, V, and Clarke, V. 2013. Successful Qualitative Research: a practical guide for beginners. London, UK: Sage. 
Camiré, M., and P. Trudel. 2010. High school athletes' perspectives on character development through sport participation. Physical Education and Sport Pedagogy, 15: 193-207.

Camiré, M., P. Trudel, and T. Forneris. 2009. High school athletes' perceptions on support, communication, negotiation and life skill development. Qualitative Research in Sport and Exercise, 1: 72-88.

Camiré, M., P. Trudel, and T. Forneris. 2012. Coaching and transferring life skills: Philosophies and strategies used by model high school coaches. The Sport psychologist, 26: $243-260$.

Camiré, M., and K. Kendellen. 2016. Coaching for positive youth development in high school sport. In Positive youth development through sport, edited by Nicholas L. Holt, 126-136. Abingdon: Routledge.

Chinkov, A.E, and N.L. Holt. 2015. Implicit transfer of life skills through participation in Brazilian Jiu-Jitsu. Journal of Applied Sport Psychology 28 (2): 139-153.

Danish, S.J. 2002. SUPER (Sports United to Promote Education and Recreation) program leader manual. $3^{\text {rd }}$ ed. Richmond, VA: Virginia Commonwealth University. Life Skills Center.

Danish. S., T. Forneris., K. Hodge, and I. Heke. 2004. Enhancing Youth Development through Sport. World Leisure Journal, 46 (3): 38-49. 
Fraser-Thomas, J., J. Côté, and J. Deakin. 2005. Youth sport programs: An avenue to foster positive youth development. Physical Education and Sport Pedagogy, 10: 19-40.

Gould, D., and S. Carson. 2008. Life skills development through sport: Current status and future directions. International Review of Sport and Exercise Psychology, 1: 5878.

Hellison, D. 2003. Teaching responsibility through physical activity. Champaign, IL: Human Kinetics.

Hodge, K., S. Danish., T. Forneris, and A. Miles. 2016. Life skills and basic psychological needs. In Positive youth development through sport, edited by Nicholas L. Holt, 126-136. London, UK: Routledge.

Hodge, K., S. Danish, and J. Martin. 2013. Developing a conceptual framework for life skills intervention. The Counseling Psychologist 41 (8): 1125-1152.

Holt, N. L., K.C., Neely., L.G. Slater., M. Camiré., J. Côté., J. Fraser-Thomas, J., D. MacDonald., L. Strachan, L. and K.A. Tamminen. 2017. A grounded theory of positive youth development through sport based on results from a qualitative metastudy. International review of sport and exercise psychology 10 (1): 1-49.

Holt, N.L., N. Tink., J.L. Mandigo, and K.R. Fox. 2008. Do youth learn life skills through their involvement in high school sport? A case study. Canadian Journal of Education 31 (2): 281-304. 
Jones, M.I., and D. Lavallee, D. 2009. Exploring perceived life skills development and participation in sport. Qualitative Research in Sport and Exercise 1: 36-50.

Jones, M.I., D. Lavallee, and D. Tod. 2011. Developing communication and organisation skills: The ELITE life skills reflective practice intervention. The Sport Psychologist 25: 35-52.

Kendellen, K., and M. Camiré. 2017. Examining the life skill development and transfer experiences of former high school athletes. International Journal of Sport and Exercise Psychology 15 (4): 395-408.

Lerner, R.M., J.V. Lerner., J.B. Almerigi., C. Theokas., E. Phelps., S. Gestsdottir., S. Naudeau., H. Jelicic., A. Alberts., L. Ma, and L.M. Smith. 2005. Positive youth development, participation in community youth development programs, and community contributions of fifth-grade adolescents: Findings from the first wave of the 4-H study of positive youth development. The Journal of Early Adolescence 25 (1): 1771.

Martinek, T., and O. Lee. 2012. From community gyms to classrooms: A framework for values-transfer in schools. Journal of Physical Education, Recreation \& Dance 83 (1): 33-51. 
Papacharisis, V., M. Goudas., S.J. Danish, and Y. Theodorakis. 2005. The effectiveness of teaching a life skills program in a sport context. Journal of Applied Sport Psychology 17: $247-254$.

Petitpas, A.J., A.E. Cornelius., J.L. Van Raalte, and T. Jones. 2005. A Framework for Planning Youth Sport Programs that Foster Psychosocial Development. The Sport Psychologist 19: 63-80.

Pierce, S., D. Gould, D. and M. Camiré. 2017. Definition and model of life skill transfer. International Review of Sport and Exercise Psychology 10 (1): 186-211.

Smith, E. 2003. Failing boys and moral panics: Perspectives on the underachievement debate. British Journal of Educational Studies, 51 (3): 282-295.

Smith, B., and K.R. McGannon. 2017. Developing rigor in qualitative research: problems and opportunities with sport and exercise psychology. International Review of Sport and Exercise Psychology, DOI: 10.1080/1750984X.2017.1317357

Sparkes, A.C., and B. Smith. 2014. Qualitative Research Methods in Sport, Exercise and Health: From Process to Product. Oxon, UK: Routledge

Theokas, C., S. Danish., K. Hodge., I. Heke, and T. Forneris. 2008. Enhancing life skills through sport for children. In Positive youth development through sport, edited by Nicholas L. Holt, 71-81. Abingdon: Routledge. 
Turnnidge, J., J. Côté, and D.J. Hancock. 2014. Positive youth development from sport to life: Explicit or implicit transfer? Quest 66: 203-217.

Walsh, D.S., J. Ozaeta, and P.M. Wright. 2010. Transference of responsibility model goals to the school environment: Exploring the impact of a coaching club program. Physical Education \& Sport Pedagogy 15: 15-28.

Weiss, M. R. 2006. The First Tee 2005 research summary: Longitudinal effects of the First Tee Life Skills Educational Program on positive youth development. St. Augustine, FL: The First Tee.

Weiss, M. R., C.P. Stuntz., J.A. Bhalla., N.D. Bolter, and M.S. Price. 2013. 'More than a game': Impact of The First Tee life skills programme on positive youth development: Project introduction and Year 1 findings. Qualitative Research in Sport, Exercise and Health 5: 214-244. 
Table 1. Overview of life skills, sports and coaching experience

\begin{tabular}{llll}
\hline Life Skill & Sport & Coach & Coaching \\
& & Demographics & Experience (Years) \\
\hline Teamwork & American Football & Female & 18 years \\
Discipline & Martial Arts & Male & 6 years \\
Goal Setting & Boxing & Female & 8.5 years \\
Concentration & Rock Climbing & Male & 10 years \\
Persistence & Frisbee & Female & 5.5 years \\
Communication & Goalball & Female & 5 years \\
Self-Confidence & Football & Male & 7 years
\end{tabular}

